\title{
Non-sterilized fermentation of high optically pure D-lactic acid by a genetically modified thermophilic Bacillus coagulans strain
}

\author{
Caili Zhang ${ }^{1 \dagger}$, Cheng Zhou ${ }^{2 \dagger}$, Nilnate Assavasirijinda ${ }^{3}$, Bo Yu ${ }^{1}$, Limin Wang ${ }^{1 *}$ (D) and Yanhe Ma ${ }^{2}$
}

\begin{abstract}
Background: Optically pure D-lactic acid ( $\geq 99 \%)$ is an important precursor of polylactic acid. However, there are relatively few studies on D-lactic acid fermentation compared with the extensive investigation of L-lactic acid production. Most lactic acid producers are mesophilic organisms. Optically pure o-lactic acid produced at high temperature not only could reduce the costs of sterilization but also could inhibit the growth of other bacteria, such as L-lactic acid producers.
\end{abstract}

Results: Thermophilic Bacillus coagulans is an excellent producer of L-lactic acid with capable of growing at $50^{\circ} \mathrm{C}$. In our previous study, the roles of two L-lactic acid dehydrogenases have been demonstrated in B. coagulans DSM1. In this study, the function of another annotated possible L-lactate dehydrogenase gene (IdhL3) was verified to be leucine dehydrogenase with an activity of 0.16 units $(\mu \mathrm{mol} / \mathrm{min})$ per $\mathrm{mg}$ protein. Furthermore, the activity of native o-lactate dehydrogenase was too low to support efficient D-lactic acid production, even under the control of strong promoter. Finally, an engineered B. coagulans D-DSM1 strain with the capacity for efficient production of D-lactic acid was constructed by deletion of two L-lactate dehydrogenases genes (IdhL1 and IdhL2) and insertion of the D-lactate dehydrogenase gene (LdldhD) from Lactobacillus delbrueckii subsp. bulgaricus DSM 20081 at the position of IdhL1.

Conclusions: This genetically engineered strain produced only D-lactic acid under non-sterilized condition, and finally $145 \mathrm{~g} / \mathrm{L}$ of D-lactic acid was produced with an optical purity of $99.9 \%$ and a high yield of $0.98 \mathrm{~g} / \mathrm{g}$. This is the highest optically pure D-lactic acid titer produced by a thermophilic strain.

Keywords: Bacillus coagulans, Genetic engineering, D-Lactic acid, Optically pure, Non-sterilized fermentation

\section{Background}

Technologies for the production of fuels and plastics from renewable biomass are currently being developed to prevent environmental pollution and global warming. Polylactic acid (PLA) is considered as an important bioplastic due to its superior thermal stability, mechanical performance, hydrolysis resistance, and excellent biodegradability $[1,2]$. Optically pure L-lactic acid ( $\geq 99 \%)$ is the main precursor of PLA, and addition of optically

\footnotetext{
*Correspondence: wanglimin@im.ac.cn

${ }^{\dagger}$ Caili Zhang and Cheng Zhou contributed equally to this work

${ }^{1}$ CAS Key Laboratory of Microbial Physiological and Metabolic Engineering, Institute of Microbiology, Chinese Academy of Sciences, Beijing 100101, People's Republic of China

Full list of author information is available at the end of the article
}

pure D-lactic acid resulted in high melting point and good appearance. So, the production of D-lactic acid has received increasing focus recently. However, both yield and productivity of $\mathrm{D}$-lactic acid are lower than those of L-lactic acid till now [3, 4]. Chemical synthesis of lactic acid leads to a racemic mixture and environmental pollution, and $70-90 \%$ of lactic acid in the world is produced by microbial fermentation in industry [5].

Compared with the extensive investigation of L-lactic acid production, there are relatively few studies on D-lactic acid fermentation [6]. Several strains have been reported to produce D-lactic acid naturally, such as $\mathrm{Lac}$ tobacillus species, Sporolactobacillus inulinus $[4,6]$. Lactic acid is generated from the conversion of pyruvate into L-lactic acid and D-lactic acid by L-lactate 
dehydrogenases (L-LDHs, encoded by $l d h L$ ) and D-lactate dehydrogenases (D-LDHs, encoded by $l d h D$ ), respectively [7]. Since D-LDHs is the key gene in D-lactic acid production, some studies reported to obtain engineered D-lactic acid producing strains with the deletion of the native $l d h L$ gene [6]. Then, some metabolically engineered strains, including Saccharomyces cerevisiae, L. plantarum, Corynebacterium glutamicum and Escherichia coli were constructed to produce D-lactic acid [8]. However, all the above strains are mesophilic and the fermentation medium needs to be sterilized, which increases the process cost. Additionally, strains have to reach certain requirements to be used in efficient lactic acid production, such as low-cost nutrition needed, high yield, high optical purity of product, low/no oxygen requirement and short fermentation time [9].

Thermophilic Bacillus coagulans almost meet all the above requirements. They can withstand various harsh conditions, such as low $\mathrm{pH}$ values, high temperatures, and no aeration [6]. Moreover, $B$. coagulans can utilize a broad range of inexpensive carbon resources, and produce optically pure L-lactic acid at $50-55{ }^{\circ} \mathrm{C}$ which is expected to minimize contamination during fermentation in industrial scale $[7,10]$. Nonsterile fermentation can omit the medium and fermentor sterilization process and largely reduce the production cost $[6,11]$. Hence, $B$. coagulans is expected to be an excellent D-lactic acid producer for industrial uses [12]. Although there are some examples about L-lactic acid production by Bacillus sp. under non-sterilized conditions, no studies about using $B$. coagulans for optically pure D-lactic acid production under non-sterilized fermentation process are reported until now [10,11].

In this study, B. coagulans DSM1, an optically pure L-lactic acid producer, was chosen for genetic engineering for D-lactic acid production. The key gene for L-lactic acid production was replaced with $L d h D$ from $L$. delbrueckii subsp. bulgaricus DSM 20081. This genetically engineered strain produced high optical purity of D-lactic acid under non-sterilized condition.

\section{Methods}

\section{Strains, plasmids and culture conditions}

Strains and plasmids used in this study are listed in Table 1 . The construction of $B$. coagulans DSM1 $\Delta$ ldhL1 $\Delta$ ldhL2, whose L-lactate dehydrogenase genes (ldhL1 and ldhL2) have been knocked out, was described previously [13]. For genetic manipulation, the $\mathrm{BC}$ medium $(50 \mathrm{~g} / \mathrm{L}$ sucrose, $10 \mathrm{~g} / \mathrm{L}$ yeast extract, $2 \mathrm{~g} / \mathrm{L}\left(\mathrm{NH}_{4}\right)_{2} \mathrm{HPO}_{4}, 3.5 \mathrm{~g} / \mathrm{L}\left(\mathrm{NH}_{4}\right)_{2} \mathrm{SO}_{4}, 10 \mathrm{~g} / \mathrm{L}$ Bis-Tris, $3 \mathrm{mg} / \mathrm{L} \mathrm{CaCl} 2,5 \mathrm{mg} / \mathrm{L} \mathrm{MgCl}_{2}, 20 \mu \mathrm{L}$ trace element mixture) was used and the culture condition was $45{ }^{\circ} \mathrm{C}$ with $120 \mathrm{rpm}$. Filter sterilized trance element mixture contained $0.2 \mathrm{mg} / \mathrm{L} \mathrm{CoCl}{ }_{2} \cdot 6 \mathrm{H}_{2} \mathrm{O}, 0.01 \mathrm{mg} / \mathrm{L} \mathrm{CuCl}_{2} \cdot 2 \mathrm{H}_{2} \mathrm{O}$,

\section{Table 1 Strains and plasmids used in this study}

\begin{tabular}{|c|c|c|}
\hline Strains or plasmids & Features & Source \\
\hline \multicolumn{3}{|l|}{ Bacillus coagulans } \\
\hline DSM1 & Wide type & DSMZ, Germany \\
\hline $\mathrm{DSM} 1 \Delta / d h \mathrm{~L} 1 \Delta / d h \mathrm{~L} 2$ & IdhL1 and IdhL2 null mutant & This study \\
\hline D-DSM1 & D-lactic acid producing strain & This study \\
\hline $\mathrm{DSM} 1 \Delta / d h \mathrm{~L} 1 \Delta / d h \mathrm{~L} 2-\mathrm{p} / d h \mathrm{~L} 1-B c / d h \mathrm{D}$ & B. coagulans DSM1 $\Delta / d h \mathrm{~L} 1 \Delta / d h \mathrm{~L} 2$ with plasmid pNW33n-p/dhL1-BcldhD & This study \\
\hline $\mathrm{DSM} 1 \Delta / d h \mathrm{~L} 1 \Delta / d h \mathrm{~L} 2-\mathrm{p} / d h \mathrm{D}-B c / d h \mathrm{D}$ & B. coagulans DSM1 $\Delta / d h L 1 \Delta / d h L 2$ with plasmid pNW33n-p/dhD-BcldhD & This study \\
\hline DSM1 $\Delta / d h L 1 \Delta / d h L 2-p / d h L 1-L d / d h D$ & B. coagulans DSM1 $\Delta / d h \mathrm{~L} 1 \Delta / d h \mathrm{~L} 2$ with plasmid pNW33n-p/dhL1-Ld/dhD & This study \\
\hline $\mathrm{DSM} 1 \Delta / d h \mathrm{~L} 1 \Delta / d h \mathrm{~L} 2-\mathrm{p} / d h \mathrm{D}-\mathrm{Ld} / d h \mathrm{D}$ & B. coagulans DSM1 $\Delta / d h \mathrm{~L} 1 \Delta / d h \mathrm{~L} 2$ with plasmid pNW33n-p/dhD-Ld/dhD & This study \\
\hline Lactococcus lactis MG1363 & Host for gene cloning & Laboratory preservation \\
\hline Escherichia coli BL21(DE3) & Host for protein expression & Tiangen Co., China \\
\hline Escherichia coli Top10 & Host for gene cloning & Tiangen Co., China \\
\hline pET-28a & Protein expression vector, $\mathrm{Kan}^{\mathrm{R}}$ & Merck Co., Germany \\
\hline pGro7 & Molecular chaperone, $\mathrm{Cm}^{\mathrm{R}}$ & TaKaRa Co., Ltd, China \\
\hline $\mathrm{pMH77}$ & pSH71 replication containing temperature sensitive vector, $\mathrm{Cm}^{\mathrm{R}}$ & Laboratory preservation \\
\hline pNW33n & E. coli-Bacillus shuttle vector, cloning vector, $\mathrm{Cm}^{\mathrm{R}}$ & BGSC, USA \\
\hline $\mathrm{pMH} 77-\mathrm{Ld} / d h \mathrm{D}$ & $L \mathrm{~d} / \mathrm{dhD}$ insert vector, $\mathrm{Cm}^{\mathrm{R}}$ & This study \\
\hline pNW33n-p/dhL1-BcldhD & $B c / d h D$ expression vector with $/ d h \mathrm{~L} 1$ promoter, $\mathrm{Cm}^{\mathrm{R}}$ & This study \\
\hline pNW33n-p/dhD-BcldhD & $B c l d h D$ expression vector with $B c l d h D$ promoter, $\mathrm{Cm}^{\mathrm{R}}$ & This study \\
\hline pNW33n-p/dhL1-Ld/dhD & IdhL1 expression vector with $\mathrm{Ld} / d h \mathrm{D}$ promoter, $\mathrm{Cm}^{\mathrm{R}}$ & This study \\
\hline pNW33n-p/dhD-Ld/dhD & IdhD expression vector with $\mathrm{Ld} / \mathrm{dhD}$ promoter, $\mathrm{Cm}^{\mathrm{R}}$ & This study \\
\hline
\end{tabular}


$0.3 \mathrm{mg} / \mathrm{L} \mathrm{H}_{3} \mathrm{BO}_{3}, 0.03 \mathrm{mg} / \mathrm{L} \mathrm{Na} \mathrm{MoO}_{4} \cdot 2 \mathrm{H}_{2} \mathrm{O}, 0.02 \mathrm{mg} / \mathrm{L}$ $\mathrm{NiSO}_{4} \cdot 6 \mathrm{H}_{2} \mathrm{O}, 0.03 \mathrm{mg} / \mathrm{L} \mathrm{MnCl}_{2} \cdot 4 \mathrm{H}_{2} \mathrm{O}$ and $0.05 \mathrm{mg} / \mathrm{L}$ $\mathrm{ZnCl}_{2}$ [14]. For fermentation, the culture condition was $50{ }^{\circ} \mathrm{C}$ with $120 \mathrm{rpm}$ in 513 medium $(50 \mathrm{~g} / \mathrm{L}$ glucose, $10 \mathrm{~g} / \mathrm{L}$ yeast extract, $30 \mathrm{~g} / \mathrm{L} \mathrm{CaCO}_{3}$ ) [10]. Plasmids based on pMH77 were constructed in Lactococcus lactis MG1363, which was grown in GM17 medium (5 g/L soy peptone, $5 \mathrm{~g} / \mathrm{L}$ tryptone, $2.5 \mathrm{~g} / \mathrm{L}$ yeast extract, $5 \mathrm{~g} / \mathrm{L}$ meat extract, $0.5 \mathrm{~g} / \mathrm{L}$ ascorbic acid, $0.25 \mathrm{~g} / \mathrm{L} \mathrm{MgSO}_{4} \cdot 7 \mathrm{H}_{2} \mathrm{O}$, $5 \mathrm{~g} / \mathrm{L} \mathrm{K} \mathrm{HPO}_{4}, 5 \mathrm{~g} / \mathrm{L}$ glycerol, $10 \mathrm{~g} / \mathrm{L}$ glucose). Plasmids based on pNW33N were constructed in E. coli TOP10 or BL21 (DE3), which was cultured in Luria-Bertani (LB) medium. When appropriate, $40 \mu \mathrm{g} / \mathrm{mL}$ kanamycin (Kan) and $25 \mu \mathrm{g} / \mathrm{mL}$ chloramphenicol $(\mathrm{Cm})$ were added to $E$. coli culture, and $7 \mu \mathrm{g} / \mathrm{mL} \mathrm{Cm}$ was added to B. coagulans and L. lactis culture.

\section{Function verification of $I d h L 3$}

Gene $l d h L 3$ was cloned to pET-28a, and the recombinant plasmid was transformed into $E$. coli BL21 (DE3). To obtain the protein, isopropyl- $\beta$-D-1thiogalactopyranoside (IPTG) was added to the culture with a final concentration of $0.5 \mathrm{mM}$ when the $\mathrm{OD}_{600}$ value reached 0.6 , and a continued culture was followed for $12 \mathrm{~h}$ at $16{ }^{\circ} \mathrm{C}$. Cells were harvested $(12,000 \times g$ for $10 \mathrm{~min}$ ) and preserved at $-80^{\circ} \mathrm{C}$. After cell sonication, $6 \times$ His-Tagged Protein Purification Kit (CWBIO, China) was applied to obtain purified protein. If inclusion body formed, molecular chaperone (Takara, China) was used to help the protein expression.

For lactate dehydrogenase, the in vitro and in vivo enzymatic activities were studied as described previously [7]. For leucine dehydrogenase, reaction was carried out with $4.5 \mathrm{mM}$ 4-methyl-2-oxopentanoate, $0.2 \mathrm{mM} \mathrm{NADH}$ and $1 \mathrm{mg}$ purified enzyme in $0.1 \mathrm{M} \mathrm{NH} \mathrm{N}_{4} \mathrm{Cl} / \mathrm{NH}_{4} \mathrm{OH}$ $(\mathrm{pH}=9.5)$ at $45{ }^{\circ} \mathrm{C}$. One unit of leucine dehydrogenase was defined as the amount of enzyme which catalyzed the consumption of $1 \mu \mathrm{mol}$ of NADH per min under the standard assay conditions. Quantitative real-time (RT)PCR was employed to determine the transcription levels of $l d h L 3$ in different fermentation periods. Total RNAs of B. coagulans DSM1 $\Delta \mathrm{ldhL} 1 \Delta \mathrm{ldhL} 2$ in logarithmic period, stationary period and decay period were isolated by using an E.Z.N.A bacterial RNA kit (Omega). With the primer pair of RTL3-F/R (Table 2), cDNA copies were synthesized with a FastQuant RT kit (with gDNase) (Tiangen,

Table 2 Primers used in this study

\begin{tabular}{|c|c|}
\hline Primers & Sequence $\left(5^{\prime} \rightarrow 3^{\prime}\right)$ \\
\hline L3-F & CCGGAATTCATGGAAATTTTTGATTATATGCG \\
\hline L3-R & CCCAAGCTTTTACCGCGGAAGCCTTTTTTC \\
\hline RTL3-F & TGAAAGAACCGAAGCACG \\
\hline RTL3-R & CCGTTCTTCCGCCATCC \\
\hline L1up-F & CCAGTACTCTGCAGAATTCGCTCCTTTCATTTGGTCAG \\
\hline L1 up-R & GTAAGCAAAAATTTTAGTCATATATAATCTTCCTCCCCATC \\
\hline D-F & GATGGGGAGGAAGATTATATATGACTAAAATTTTTGCTTAC \\
\hline D-R & GAAGCCCGGCCGGCACAAATGCTTAGCCAACCTTAACTGGAG \\
\hline L1down-F & CTCCAGTTAAGGTTGGCTAAGCATTTGTGCCGGCCGGGCTTC \\
\hline L1down-R & GCCGAAAATATGCACTCGAGGATCAACCGGGTCAGTGCAG \\
\hline 77-F & CTGCACTGACCCGGTTGATCCTCGAGTGCATATTTTCGGC \\
\hline $77-\mathrm{R}$ & CTGACCAAATGAAAGGAGCGAATTCTGCAGAGTACTGG \\
\hline pL1D-L1F & CGGGGTACCAGCCTCATCGCCGGTTTCC \\
\hline pL1D-L1R & TAGGCAACAACTTTTCTCATATATAATCTTCCTCCCCATC \\
\hline pL1D-DF & GATGGGGAGGAAGATTATATATGAGAAAAGTTGTTGCCTA \\
\hline pL1D-DR & CCCAAGCTTTCATACTTTTATCTCCCACCTGCTC \\
\hline pDD-F & CGGGGTACCGCATTCGTCTGAGTGGGCC \\
\hline pDD-R & CCCAAGCTTTCATACTTTTAATCTCCCACCTG \\
\hline pL1LD-pL1F & GATTGTGAAATTGAATTCGAGCTCGGTACCAGCCTCATCGCCGGTTTCCCTCGC \\
\hline pL1LD-LDR & GAAACAGCTATGACCATGATTACGCCAAGCTTTTAGCCAACCTTAACTGGAGTTTC \\
\hline pDLD-pDF & CTGATTGTGAAATTGAATTCGAGCTCGGTACCGCATTCGTCTGAGTGGGCCAAGG \\
\hline pDLD-pDR & GTAAGCAAAAATTTTAGTCATACGACAGCTTCCTTTCCATTC \\
\hline pDLD-LDF & GAATGGAAAGGAAGCTGTCGTATGACTAAAATTTTTGCTTAC \\
\hline pDLD-LDR & CTATGACCATGATTACGCCAAGCTTGCATGCCTGCAGTTAGCCAACCTTAACTGGAG \\
\hline
\end{tabular}

Restriction sites in the primer sequences are underlined 
China) and amplified with SYBR Premix Ex Taq (TaKaRa, China). The threshold cycles $\left(C_{T}\right)$ for each PCR were analyzed according to the Ref. [13].

\section{Functional study of native IdhD in B. coagulans DSM1}

The D-lactate dehydrogenase encoding gene from $B$. coagulans DSM1 (BcldhD) and L. delbrueckii subsp. bulgaricus DSM 20081 (LdldhD) were cloned to pNW33n under the control of the strong promoter of $l d h L 1$ promotor $\left(\mathrm{P}_{\text {ldhL1 }}, 1182 \mathrm{bp}\right)$ and the native promoter of BcldhD $\left(\mathrm{P}_{B c l d h D}\right)$, respectively. In total, four recombinant plasmids in pNW33n, named as $\mathrm{P}_{l d h L 1}-B c l d h D$,

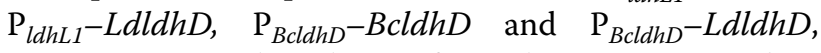
were constructed and transformed into $B$. coagulans DSM1 $\Delta$ ldhL1 $\Delta \mathrm{ldhL} 2$. The concentration of D-lactic acid was measured.

\section{Gene insertion in B. coagulans DSM1 $\Delta \mathrm{ldhL} 1 \Delta \mathrm{ldhL2}$}

Plasmid pMH77 was used as the primary vehicle to transfer ldhD from L. delbrueckii (LdldhD) to B. coagulans DSM1 $\Delta \mathrm{ldhL} 1 \Delta \mathrm{ldhL} 2$ in the original positon of ldhL1 (Fig. 1). Primers used for gene insertion are listed in Table 2. Homologous arms of the upstream (1000 bp) and downstream (1000 bp) sequence of ldhL1 were PCR amplified with primers L1up-F/R and L1downF/R, respectively. $L d l d h D$ and $\mathrm{pMH77}$ were amplified by primers DS-F/R and 77-F/R correspondingly. Then four fragments were connected by Clone Express ${ }^{\circledR}$ MultiS One Step Cloning Kit (Vazyme Biotech Co., Ltd) resulting in plasmid $\mathrm{pMH} 77-L d l d h D$.

Plasmid pMH77-LdldhD was firstly transformed into L. lactis MG1363 by electroporation. After verifying the correctness by sequencing, pMH77-LdldhD was transformed into B. coagulans DSM1 $\Delta \mathrm{ldhL} 1 \Delta \mathrm{ldhL} 2$ by electroporation. The transformants were cultured in $\mathrm{BC}$ medium with $\mathrm{Cm}$ at $45^{\circ} \mathrm{C}$ for $6-10 \mathrm{~h}$ to mid-log phase and then the temperature was shifted to $60{ }^{\circ} \mathrm{C}$ for overnight [14]. A dilution series were plated on $B C$ plates with $\mathrm{Cm}$ and incubated overnight at $60{ }^{\circ} \mathrm{C}$. Colony PCR analysis was carried out for the first single crossover event. The positive clones were selected to be incubated in BC medium without $\mathrm{Cm}$ overnight at $45{ }^{\circ} \mathrm{C}$. The obtained single colonies were firstly streaked onto $\mathrm{BC}$ plates with $\mathrm{Cm}$ and then without $\mathrm{Cm}$. After incubation overnight at $45{ }^{\circ} \mathrm{C}, \mathrm{PCR}$ analysis using the primers DS-For/Rev was conducted for the colonies which could grow on $\mathrm{BC}$

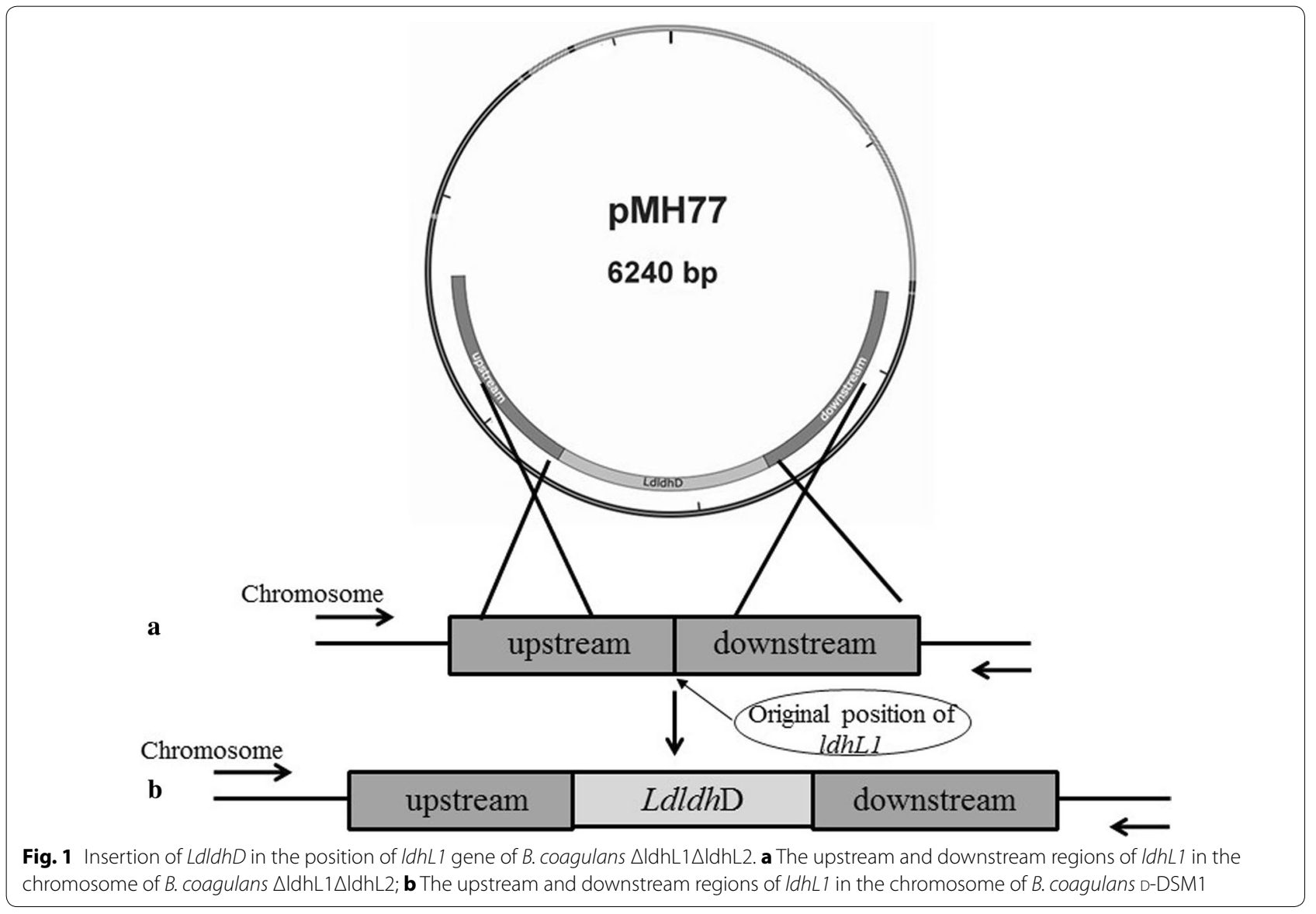


plates without $\mathrm{Cm}$ and could not grow on $\mathrm{BC}$ plates with $\mathrm{Cm}$. The positive colonies were sequenced to confirm the gene insertion.

\section{Non-sterilized fermentation of D-lactic acid by $B$. coagulans D-DSM1}

The seed cultures were prepared in 513 medium for $24 \mathrm{~h}$ and then inoculated with $10 \%(\mathrm{v} / \mathrm{v})$ in the fermentation medium. The fermentation medium was maintained at approximately $\mathrm{pH} 5.5-6.0$ with the addition of $\mathrm{CaCO}_{3}$. Fed-batch fermentation was carried out at $50{ }^{\circ} \mathrm{C}$ with $50 \mathrm{rpm}$ in a 5-L bioreactor with $2 \mathrm{~L}$ fresh medium without sterilization. The initial glucose concentration was $50 \mathrm{~g} / \mathrm{L}$. When the glucose concentration decreased to lower than $20 \mathrm{~g} / \mathrm{L}$, glucose powder was added directly and repeatedly, leading to the result that the glucose concentration reached to approximately $50 \mathrm{~g} / \mathrm{L}$ for 4 times.

\section{Analytical methods}

Glucose consumption and lactate production were measured by HPLC (Agilent 1260 Series, Hewlett-Packard, Palo Alto, CA, USA) with an organic-acid column (MCI GEL CRS10W). The mobile phase was $6 \mathrm{mM}$ $\mathrm{H}_{2} \mathrm{SO}_{4}$ and the flow rate was $0.5 \mathrm{~mL} / \mathrm{min}$. Temperature of the column was set to $55{ }^{\circ} \mathrm{C}$. Both UV and differential detector were involved in the detection and the UV detection wavelength was $210 \mathrm{~nm}$. The chiral and optical purity of D-lactic acid were analyzed using HPLC with a chiral column (MCI GEL CRS10W, Tokyo, Japan) [15]. Mobile phase was $2 \mathrm{mM} \mathrm{CuSO}_{4}$ at a flow rate of $0.5 \mathrm{~mL} / \mathrm{min}$. Column temperature was set to $25^{\circ} \mathrm{C}$ and UV detection wavelength was $254 \mathrm{~nm}$. The optical purity of D-lactic acid was calculated through the following formula: D-lactic acid optical purity $=$ D-lactic acid $/$ (D-lactic acid + L-lactic acid) $\times 100 \%$. For the growth monitoring, $\mathrm{A}_{600}$ was measured by a 7200 Visible Spectrophotometer (UNICO, Shanghai, China).

\section{Results}

L-Lactate dehydrogenase gene (IdhL3) in B. coagulans DSM1 $\Delta$ ldhL1 $\Delta$ ldhL2

Three genes (ldhL1, ldhL2 and ldhL3) related to L-lactic acid production were annotated in the genome of B. coagulans DSM1 (GenBank accession number CP009709). Gene $l d h L 1$ plays a major role in L-lactic acid production, and no L-lactic acid was detected in B. coagulans DSM1 $\Delta \mathrm{ldhL} 1 \Delta \mathrm{ldhL2}$ [13]. Gene ldhL3 is annotated as leucine dehydrogenase/L-lactate dehydrogenase. To verify the function of $l d h L 3, \mathrm{~L}-\mathrm{LDH} 3$ (encoded by ldhL3) was expressed solubly in E. coli with the help of molecular chaperone $p$ Gro7 [16]. The purified protein has the activity of leucine dehydrogenase with 0.16 units $(\mu \mathrm{mol} / \mathrm{min})$ per $\mathrm{mg}$ protein. RT-PCR and protein mass spectrometry studies showed that $l d h L 3$ expressed at both transcription level and protein level. However, neither D-lactate nor L-lactate was detected in the reaction product of purified L-LDH3 by HPLC. Although purified L-LDH3 could catalyzed the oxidation of NADH, only leucine dehydrogenase activity was detected. So, there is no L-LDH activity in $B$. coagulans DSM1 $\Delta \mathrm{ldhL} 1 \Delta \mathrm{ldhL}$, which makes the strain as a candidate for producing high optical purity of D-lactate.

\section{The activity of the native D-lactic acid dehydrogenase in DSM1 1 IdhL1 $\Delta$ IdhL2}

A D-LDH-encoding gene BcldhD was annotated in B. coagulans DSM1 $\Delta \mathrm{ldhL} 1 \Delta \mathrm{ldhL} 2$, and our previous study showed that the native D-LDH has an activity of $1.87 \pm 0.08 \mathrm{U} / \mathrm{mg}$ in vitro $[7,13]$. So, we firstly tried to detect the concentration of $\mathrm{D}$-lactic acid produced by its native D-LDH in B. coagulans DSM1 $\Delta \mathrm{ldhL} 1 \Delta \mathrm{ldhL} 2$. However, only trace amount of D-lactic acid $(0.26 \mathrm{~g} / \mathrm{L})$ was obtained (Additional file 1: Figure S1), and the growth of strain was poor when L-LDH genes deleted [13]. For $B$. coagulans DSM1, L-LDH deletion did not increase the expression or activity of native $\mathrm{D}-\mathrm{LDH}$. To trace the reason, a plasmid containing $l d h L 1$ promoter and native $l d h D$ from $B$. coagulans DSM1 (BcldhD) was first constructed by using plasmid pNW33N $\left(\mathrm{P}_{l d h L 1}-\right.$ BcldhD) and introduced into DSM1 $\Delta \mathrm{ldhL} 1 \Delta \mathrm{ldhL} 2$. Unfortunately, there was no difference in the concentrations of D-lactic acid between strain DSM1 $\Delta \mathrm{ldhL} 1 \Delta \mathrm{ldhL} 2$ carrying $\mathrm{P}_{l d h L 1}-B$ cldhD $(0.15 \pm 0.03 \mathrm{~g} / \mathrm{L})$ and strain DSM1 $\Delta \mathrm{ldhL} 1 \Delta \mathrm{ldhL} 2(0.16 \pm 0.05 \mathrm{~g} / \mathrm{L})$ (Fig. 2). It seems that the enzyme activity of the native D-LHD in DSM1 was very low. $L$. delbrueckii subsp. bulgaricus DSM20081 is a D-lactic acid producer. The D-LDH (encoded by $L d l d h D$ ) plays a central role in D-lactic acid production with a high catalytic efficiency $\left(k_{\text {cat }}\right)$ of $235.5 \pm 1.6 \mathrm{~s}^{-1}$ [7]. To further investigate the mechanism, two strains carrying $L d l d h D$ under the control of BcldhD promoter $\left(\mathrm{P}_{B c l d h}-L d l d h D\right)$ and $l d h L 1$ promoter from DSM1 $\left(\mathrm{P}_{\text {ldhL1 }}-\right.$ LdldhD $)$ were constructed, respectively. Results showed that $46.14 \pm 0.52$ and $45.05 \pm 0.47 \mathrm{~g} / \mathrm{L}$ D-lactic acid were obtained, with a yield of 0.98 and $0.96 \mathrm{~g} / \mathrm{g}$, respectively (Fig. 2). Same glucose consumption rates and $\mathrm{OD}_{600}$ values were also observed in both strains.

\section{B. coagulans D-DSM1 construction by introducing LdIdhD}

Since the native D-lactate dehydrogenase could not support the efficient D-lactic acid production in the $l d h L$ knockout strain, the $l d h D$ gene from $L$. delbrueckii subsp. bulgaricus DSM20081 were introduced into B. coagulans DSM1 $\Delta \mathrm{ldhL} 1 \Delta \mathrm{ldhL} 2$ at the position of $l d h L 1$, which is driven by the native promoter of $l d h L 1$ (Fig. 1). Using the primers of DS-For/Rev, a 3002 bp-band was detected by 

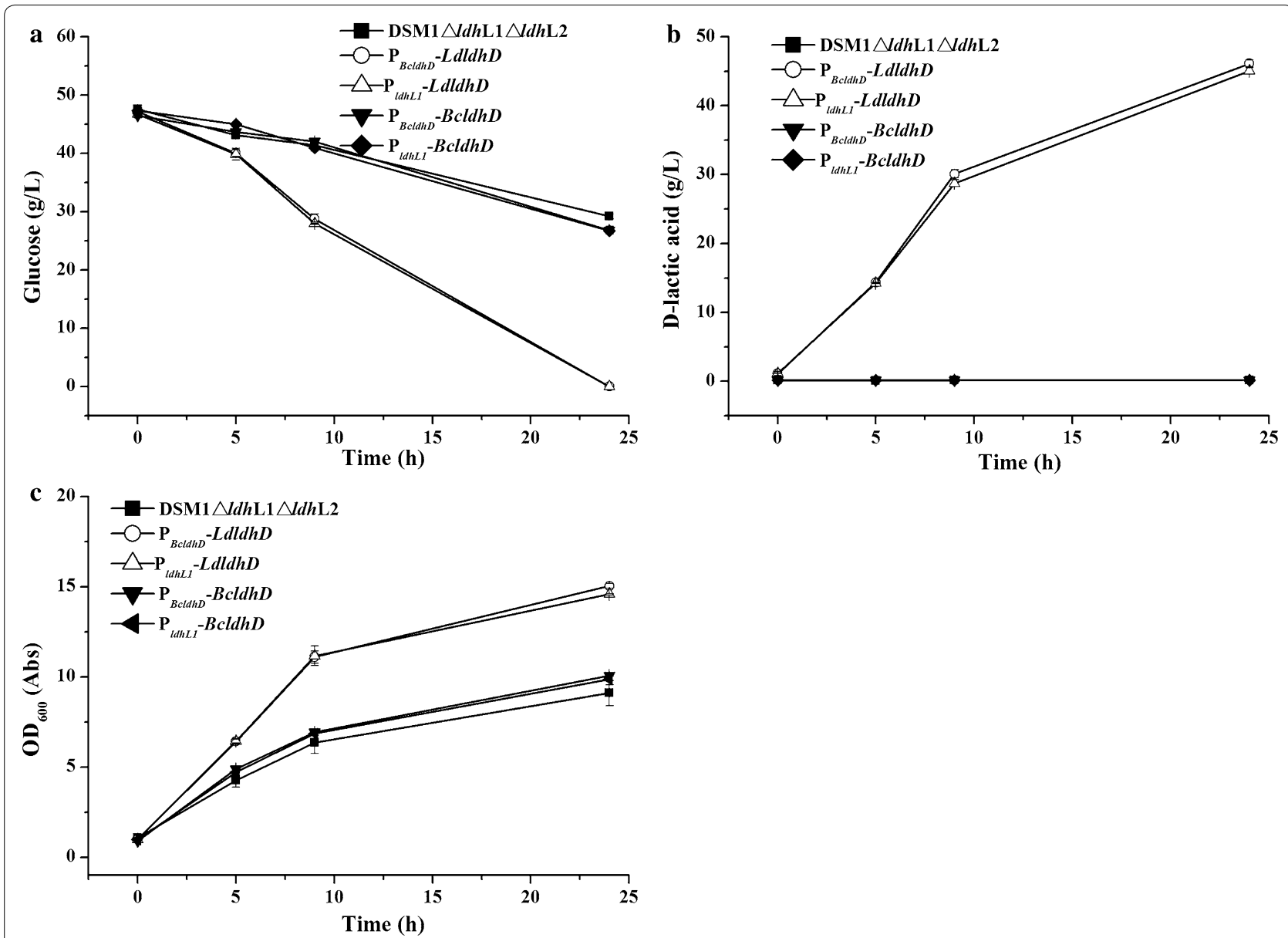

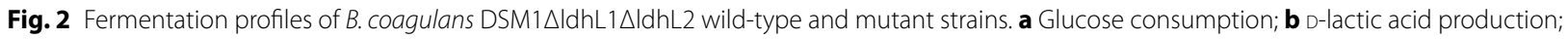
c $\mathrm{A}_{600}$ value. Each data point represents the average of three replicates, with the error bars representing the standard deviation

PCR amplification, which means that the gene $L d l d h D$ had been inserted into the positon of $l d h L 1$ in B. coagulans DSM1 $\Delta \mathrm{ldhL} 1 \Delta \mathrm{ldhL} 2$ (Additional file 1: Figure S2). The resultant strain $l d h L 1:: L d l d h D$ was named as $B$. coagulans D-DSM1.

Strain B. coagulans D-DSM1 produced $48.65 \mathrm{~g} / \mathrm{L}$ D-lactic acid with an initial glucose concentration of 50 and $117.96 \mathrm{~g} / \mathrm{L}$ D-lactic acid with an initial glucose concentration of $120 \mathrm{~g} / \mathrm{L}$ (Table 3). The optical purities were around $99.0-99.6 \%$. To investigate the source of $\mathrm{L}$-lactic

Table 3 D-Lactic acid fermentation with different initial glucose concentrations by B. coagulans D-DSM1

\begin{tabular}{lllll}
\hline $\begin{array}{l}\text { Glucose } \\
\text { (g/L) }\end{array}$ & $\begin{array}{l}\text { D-Lactic acid } \\
\text { (g/L) }\end{array}$ & Yield (g/g) & $\begin{array}{l}\text { Productivity } \\
\text { (g/L/h) }\end{array}$ & $\begin{array}{l}\text { Optical } \\
\text { purity } \\
(\%)\end{array}$ \\
\hline 50 & $48.65 \pm 0.43$ & 0.97 & $2.03 \pm 0.03$ & 99.0 \\
120 & $117.96 \pm 0.73$ & 0.98 & $1.97 \pm 0.03$ & 99.6 \\
\hline
\end{tabular}

acid in the broth, different yeast extraction concentration of 10,5 and $1 \mathrm{~g} / \mathrm{L}$ was added to the fermentation medium. At $0 \mathrm{~h}, 0.6 \mathrm{~g} / \mathrm{L} \mathrm{L}$-lactic acid was detected in the medium with $10 \mathrm{~g} / \mathrm{L}$ yeast extract, and the concentration was finally leveling out at $0.6 \mathrm{~g} / \mathrm{L}$ during fermentation. The optical purity of D-lactate was $99.0,99.5$ and $100 \%$ respectively at $24 \mathrm{~h}$. Therefore, it was concludes that the trace amount of $\mathrm{L}$-lactic acid came from yeast extract and not from the endogenous metabolism of D-DSM1. Acetic acid $(0.35 \pm 0.02 \mathrm{~g} / \mathrm{L})$ and pyruvate $(0.03 \pm 0.00 \mathrm{~g} / \mathrm{L})$ were also found in the fermentation broth, and no ethanol, oxaloacetic acid and formic acid were detected (Additional file 1: Figure S3).

\section{Non-sterilized fed-batch fermentation of D-lactic acid}

Non-sterilized fermentation of D-lactic acid production was performed in a 5-L bioreactor with fed-batch strategy. The initial glucose concentration was $50 \mathrm{~g} / \mathrm{L}$. When residual glucose decreased to approximately $20 \mathrm{~g} / \mathrm{L}$, glucose was added to a concentration of $50 \mathrm{~g} / \mathrm{L}$. During the 
first $12 \mathrm{~h}$, the concentration of glucose decreased rapidly from 50 to $20 \mathrm{~g} / \mathrm{L}$. The final concentration of D-lactic acid reached $145.23 \pm 0.82 \mathrm{~g} / \mathrm{L}$ with a yield of $0.98 \mathrm{~g} / \mathrm{g}$ and a productivity of $1.51 \pm 0.05 \mathrm{~g} / \mathrm{L} / \mathrm{h}$ (Fig. 3). Since yeast extract contained a small amount of L-lactic acid $(0.4 \mathrm{~g} / \mathrm{L}$ at $0 \mathrm{~h}$ ), the optical purity of D-lactic acid was just $91.6 \%$ at $0 \mathrm{~h}$ and increased gradually to $99.2 \%$ at $24 \mathrm{~h}$. Interestingly, the optical purity achieved about $100 \%$ at the end of fermentation (Fig. 4).

\section{Discussion}

Poly-D-lactic acid is an important polymer because it improves the thermostability of poly-L-lactic acid through stereo complex formation. However, fermentation of D-lactic acid monomer has been little studied in

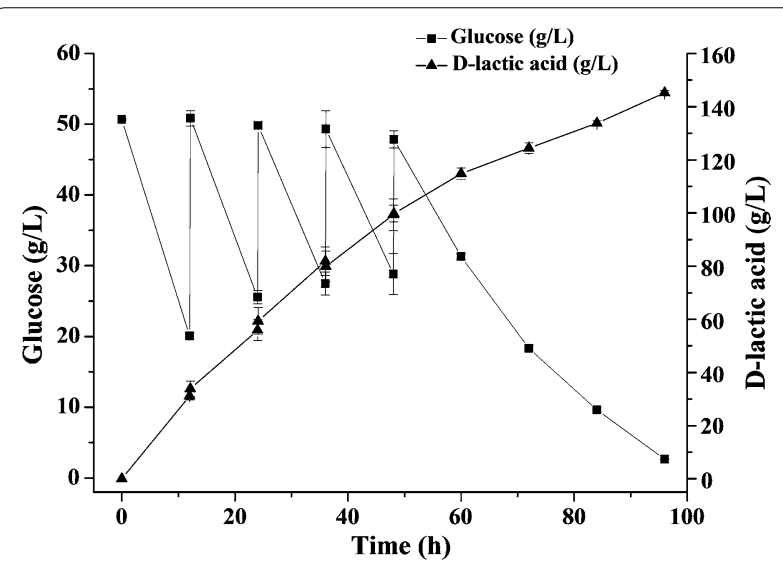

Fig. 3 Non-sterilized fed-batch fermentation of B. coagulans D-DSM1. Each data point represents the average of three replicates, with the error bars representing the standard deviation

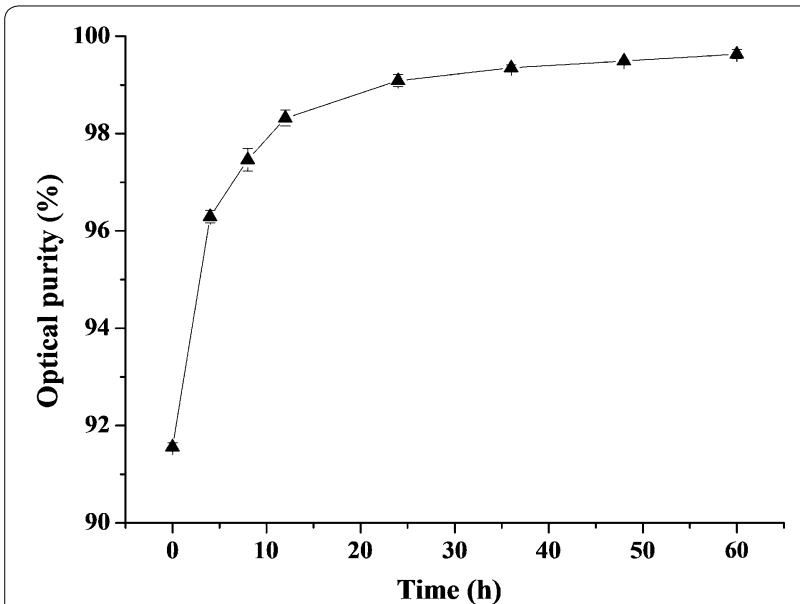

Fig. 4 Optical purity of D-lactic acid in non-sterilized fed-batch fermentation of $B$. coagulans D-DSM1. Each data point represents the average of three replicates, with the error bars representing the standard deviation comparison with L-lactic acid [17]. Till now, most D-lactic acid producing strains are mesophilic microorganisms, whose growth temperature is between 30 and $42{ }^{\circ} \mathrm{C}$ (Table 4) [6]. For example, Yamada et al. reported that $60 \mathrm{~g} / \mathrm{L}$ D-lactic acid was obtained by genetically manipulated S. cerevisiae at $30{ }^{\circ} \mathrm{C}$ [18]. The main drawback of D-lactic acid production by mesophilic microorganisms is the contamination during fermentation, because most species of L-lactic acid producers display mesophilic properties. To overcome such technical shortcomings, strains with thermotolerant characteristics are highly desirable. Tashiro et al. isolated a strain named $L$. delbrueckii subsp. lactis QU 41, which could produce D-lactic acid at $49-55{ }^{\circ} \mathrm{C}[4]$. B. coagulans strains typically produce L-lactic acid with low or undetectable level of D-lactic acid. Compared to the most of D-lactic acid producers, such as L. bulgaricus, L. delbrueckii and L. plantarum, $B$. coagulans does not need complex nutrients and require less cooling [19]. B. coagulans could growth under micro aerobic conditions, which do not need oxygen application and high-speed agitation during lactic acid production. So, B. coagulans is an promising host with robustness for D-lactic acid production.

The key enzymes of lactic acid production are lactate dehydrogenases. L-lactate dehydrogenases (L-LDHs) are responsible for L-lactic acid production and D-lactate dehydrogenases (D-LDHs) are responsible for $\mathrm{D}$-isomer production [7]. So many genetic modifications of strains focused on encoding genes of above two enzymes [2023]. Actually, a D-lactic acid producing strain B. coagulans QZ19 was constructed by deleting the native ldhL and als $S$ (acetolactate synthase encoding gene) to impede anaerobic growth. Combing the growth-based selection, glycerol dehydrogenase was found to have the ability of D-LDH. Finally, $90 \mathrm{~g} / \mathrm{L}$ of optically pure D-lactic acid was produced after a long time metabolic evolution in batch fermentation [12]. Low D-lactic acid titer hinders the further use for this strain. B. coagulans DSM1 is a homo-fermentative L-lactic acid producer. Three L-lactate dehydrogenase (L-LDH) encoding genes (ldhL1, $l d h L 2$ and $l d h L 3)$ were discerned according to the wholegenome sequence of $B$. coagulans DSM1. The key roles of $l d h L 1$ and $l d h L 2$ have been systematically studied in our previous paper [13]. Both L-LDH1 (encoded by ldhL1, $5.27 \pm 0.14 \mathrm{U} / \mathrm{mg}$ ) and L-LDH2 (encoded by $l d h L 2$, $4.53 \pm 0.26 \mathrm{U} / \mathrm{mg}$ ) were found to have catalytic activities in vitro. However, no transcription level was detected in $l d h L 2$ in vivo. Deletion of the $l d h \mathrm{~L} 2$ gene revealed no difference in fermentation profile compared to the wildtype strain, while $l d h \mathrm{~L} 1$ single deletion or $l d h \mathrm{~L} 1 l d h \mathrm{~L} 2$ double deletion completely blocked L-lactic acid production. Therefore, the genes encoding L-LDH1 (ldhL1) was inferred to contribute to L-lactic acid synthesis in $B$. 
Table 4 Comparison of $D$-lactic acid production by recombinants strains

\begin{tabular}{|c|c|c|c|c|c|c|c|c|c|}
\hline Organism & $\begin{array}{l}\text { Fermentation } \\
\text { temperature } \\
\left({ }^{\circ} \mathrm{C}\right)\end{array}$ & $\begin{array}{l}\text { Fermenta- } \\
\text { tion mode }\end{array}$ & $\mathrm{pH}$ & $\begin{array}{l}\text { D-Lactate } \\
\text { concentra- } \\
\text { tion }(\mathrm{g} / \mathrm{L})\end{array}$ & Total sugar addition & $\begin{array}{l}\text { Yield } \\
(\mathbf{g} / \mathbf{g})^{\mathrm{a}}\end{array}$ & $\begin{array}{l}\text { Productivity } \\
(\mathrm{g} / \mathrm{L} / \mathrm{h})^{\mathrm{b}}\end{array}$ & $\begin{array}{l}\text { Optical } \\
\text { purity (\%) }\end{array}$ & References \\
\hline $\begin{array}{l}\text { Saccharomyces } \\
\text { cerevisiae }\end{array}$ & 30 & Batch & - & 60 & $100 \mathrm{~g} / \mathrm{L}$ (glucose) & 0.65 & 2.8 & 99.9 & [18] \\
\hline $\begin{array}{l}\text { Pediococcus } \\
\text { acidilactici }\end{array}$ & 42 & SSF & - & 97 & $25 \%(w / w$, corn stover $)$ & 0.93 & 1.0 & 99.1 & [24] \\
\hline $\begin{array}{l}\text { Lactobacillus } \\
\text { plantarum }\end{array}$ & 37 & SSF & $5.5-6.0$ & 117 & $20 \%$ (w/v, brown rice) & 0.93 & 0.8 & 99.6 & [2] \\
\hline $\begin{array}{l}\text { Saccharomyces } \\
\text { cerevisiae }\end{array}$ & 30 & Fed-batch & - & 112 & 190 g/L (glucose) & 0.80 & 2.2 & - & {$[25]$} \\
\hline Escherichia coli & 35 & Batch & 7.0 & 96 & $10 \%(w / V$, sucrose $)$ & 0.93 & 2.6 & $>99.5$ & [26] \\
\hline $\begin{array}{l}\text { Sporolactoba- } \\
\text { cillus inulinus }\end{array}$ & 42 & Batch & 5.0 & 93 & $100 \mathrm{~g} / \mathrm{L}$ (glucose) & 0.93 & 1.1 & - & [27] \\
\hline Bacillus sp. & 54 & Batch & 6.5 & 28 & $50 \mathrm{~g} / \mathrm{L}$ (sucrose) & 0.96 & - & 99.5 & [23] \\
\hline $\begin{array}{l}\text { Bacillus coagu- } \\
\text { lans }\end{array}$ & 50 & Batch & 5.0 & 90 & $110 \mathrm{~g} / \mathrm{L}$ (glucose) & 0.96 & 1.3 & 100 & [12] \\
\hline $\begin{array}{l}\text { Bacillus coagu- } \\
\text { lans }\end{array}$ & 50 & Batch & $5.5-6.0$ & 118 & $120 \mathrm{~g} / \mathrm{L}$ (glucose) & 0.98 & 2.0 & 99.6 & This study \\
\hline $\begin{array}{l}\text { Bacillus coagu- } \\
\text { lans }\end{array}$ & 50 & Fed-batch & $5.5-6.0$ & 145 & $150 \mathrm{~g} / \mathrm{L}$ (glucose) & 0.98 & 1.5 & 99.9 & This study \\
\hline
\end{tabular}

coagulans DSM1. Because lactate dehydrogenases drive the consumption of NADH, which is an important step in the metabolism and energy conversion of living cells, ldhL1 deletion may provoke the increased expression of other NADH consumption enzymes, such as L-LDH2 [21]. So, B. coagulans DSM1 $1 \mathrm{ldhL} 1 \Delta \mathrm{ldhL} 2$ was used as a candidate in this study.

Because gene ldhL3 is annotated as leucine dehydrogenase/L-lactate dehydrogenase, the enzymatic characterization of L-LDH3 (encoded by ldhL3) was firstly studied. L-LDH3 was confirmed to be leucine dehydrogenase. There is no L-LDHs in B. coagulans DSM1 $\Delta$ ldhL1 $\Delta$ ldhL2. Then we tried to use the native D-LDH encoding gene BcldhD from B. coagulans DSM1 to construct the D-lactic acid producer. However, only trace amount of D-lactic acid was produced in B. coagulans DSM1 $\Delta \mathrm{ldhL1} \Delta \mathrm{ldhL} 2$, and the growth of strain was poor when L-LDH encoding genes deleted (Additional file 1: Figure S1) [12]. To trace the reason for low D-lactic acid production, D-lactic acid productions using four recombinants, expressing different $\mathrm{D}-\mathrm{LDH}$ encoding genes under the control of BcldhD promoter $\left(\mathrm{P}_{B c l d h D}\right)$ and ldhL1 promoter $\left(\mathrm{P}_{l d h L 1}\right)$ respectively, were performed. The introduction of $B c l d h D$ under the control of $\mathrm{P}_{B c l d h D}$ or $\mathrm{P}_{l d h L 1}$ led to low production of $\mathrm{D}$-lactic acid and low consumption of glucose. However, the introduction of a D-LDH encoding gene $L d l d h D$ from $L$. delbrueckii subsp. bulgaricus DSM20081 under the control of $\mathrm{P}_{B c l d h D}$ or $\mathrm{P}_{l d h L 1}$ resulted in high production of $\mathrm{D}$-lactic acid and high consumption of glucose (Fig. 2), which suggested that the activity of native promoter of $B c l d h D$ functioned enough to drive the gene expression. Even when strong promoter $\left(\mathrm{P}_{l d h L 1}\right)$ was introduced to drive the high expression of BcldhD, the enzyme of $\mathrm{D}-\mathrm{LDH}$ from strain DSM1 did not show sufficient activity. So, the activity of native $\mathrm{D}$-LDH was too low to support the efficient D-lactic acid production.

Lactobacillus delbrueckii subsp. bulgaricus DSM20081 is a D-lactic acid producer. Its key enzyme D-LDH, encoded by $L d l d h \mathrm{D}$, exhibited a high catalytic efficiency [7]. Most importantly, D-LDH from strain DSM20081 could work at the temperature at $50{ }^{\circ} \mathrm{C}$, which is consistent with the growth temperature of $B$. coagulans (Additional file 1: Figure S4). Gene $L d l d h D$ from strain DSM20081 was inserted into the original location of $l d h L 1$ using the $l d h L 1$ promoter (Fig. 1). The obtained strain D-DSM1 produced $145 \mathrm{~g} / \mathrm{L}$ D-lactic acid in fedbatch fermentation, with a yield of $0.98 \mathrm{~g} / \mathrm{g}$ and an optical purity of $99.9 \%$ (Fig. 3), and 118 g/L D-lactic acid with a yield of $0.98 \mathrm{~g} / \mathrm{g}$ was obtained in batch fermentation (Table 3). Attempts have been made to produce D-lactic acid using Lactic Acid Bacteria and E. coli $[2,26]$. Some acid-tolerant strains, such as $S$. cerevisiae, $P$ acidilactici, $S$. inulinus, were also engineered to produce D-lactic acid 
[18, 24, 25, 27]. However, low D-lactic acid concentration was obtained under non-neutralized condition [25]. Actually, most strains are mesophilic (Table 4). A D-lactic acid producing strain was constructed based on a thermophilic Bacillus strain and $28 \mathrm{~g} / \mathrm{L}$ D-lactic acid with an optical purity of $99.5 \%$ was obtained [23]. For thermophilic organism, the maximal yield of D-lactic acid was $90 \mathrm{~g} / \mathrm{L}$ in batch fermentation [12]. In this study, besides metabolic engineering, also process optimization was carried out to obtain a thermophilic D-lactic-acid-producing strain. Compared with the existing D-lactic acid producing strains, strain D-DSM1 obtained in this study is more suitable for industry uses with high D-lactic acid titer $(145 \mathrm{~g} / \mathrm{L})$ and high optical purity (99.9\%). Until now, it is the highest D-lactic acid titer produced by thermotolerant strains (Table 4).

In conclusion, this present strain D-DSM1, which expresses $L d l d h \mathrm{D}$ from $L$. delbrueckii subsp. bulgaricus DSM20081 under the control of the native $l d h L 1$ promoter, produced D-lactic acid with high yield $(0.98 \mathrm{~g} / \mathrm{g})$ and high optical purity (99.9\%). Furthermore, non-sterilized fermentation was conducted which would significantly lower the fermentation costs and nutrition loss, and thus increase the economy of the fermentation process. B. coagulans D-DSM1 could be a promising D-lactic acid producer in industrial settings.

\section{Additional file}

Additional file 1. Additional figures.

\section{Authors' contributions}

LW and BY designed the project; CLZ and CZ performed experiments; LW, NA and YM analyzed the data; LW wrote the manuscript. All authors read and approved the final manuscript.

\section{Author details}

${ }^{1}$ CAS Key Laboratory of Microbial Physiological and Metabolic Engineering, Institute of Microbiology, Chinese Academy of Sciences, Beijing 100101, People's Republic of China. ${ }^{2}$ State Key Laboratory of Microbial Resources, Institute of Microbiology, Chinese Academy of Sciences, Beijing 100101, People's Republic of China. ${ }^{3}$ Department of Biology, Faculty of Science, King Mongkut's Institute of Technology Ladkrabang, Bangkok 10520, Thailand.

\section{Acknowledgements}

The work was supported by grants from the National Natural Science Foundation of China (31670045), the Project of Guangxi Provincial Science \& Technology Development, China and the Key International Cooperation Project from Chinese Academy of Sciences (155112KYSB20160010-02). The work was partially supported by grant from the Key International Cooperation Project of Chinese Academy of Sciences (155112KYSB20150024).

\section{Competing interests}

The authors declare that they have no competing interests.

\section{Availability of data and materials}

All data and materials are available.

\section{Consent for publication}

All the authors give their consents to the publication.
Ethics approval and consent to participate Not applicable.

\section{Funding}

The work was funded by grants from the National Natural Science Foundation of China (31670045).

\section{Publisher's Note}

Springer Nature remains neutral with regard to jurisdictional claims in published maps and institutional affiliations.

Received: 10 August 2017 Accepted: 16 November 2017

Published online: 25 November 2017

\section{References}

1. Marius M, Philippe D. PLA composites: from production to properties. Adv Drug Deliv Rev. 2016;107:17-46.

2. Okano K, Hama S, Kihara M, Noda H, Tanaka T, Kondo A. Production of optically pure D-lactic acid from brown rice using metabolically engineered Lactobacillus plantarum. Appl Microbiol Biotechnol. 2017;101:1869-75.

3. Södergard A, Stolt M. Properties of lactic acid based polymers and their correlation with composition. Prog Polym Sci. 2002;27:1123-63.

4. Tashiro Y, Kaneko W, Sun Y, Shibata K, Inokuma K, Zendo T, Sonomoto K. Continuous D-lactic acid production by a novel thermotolerant Lactobacillus delbrueckii subsp. lactis QU 41. Appl Microbiol Biotechnol. 2011:89:1741-50.

5. Ghaffar T, Irshad M, Anwar Z, Aqil T, Zulifqar Z, Tariq A, Kamran M, Ehsan N, Mehmood S. Recent trends in lactic acid biotechnology: a brief review on production to purification. J Radiat Res Appl Sci. 2014;7:222-9.

6. Wang L, Zhao B, Li F, Xu K, Ma C, Tao F, Li Q, Xu P. Highly efficient production of D-lactate by Sporolactobacillus sp. CASD with simultaneous enzymatic hydrolysis of peanut meal. Appl Microbiol Biotechnol. 2011;89:1009-17

7. Wang L, Cai Y, Zhu L, Guo H, Yu B. Major role of NAD-dependent lactate dehydrogenases in high optically pure L-lactic acid production by thermophilic Bacillus coagulans. Appl Environ Microbiol. 2014;80:7134-41.

8. Zheng L, Liu M, Sun J, Wu B, He B. Sodium ions activated phosphofructokinase leading to enhanced D-lactic acid production by Sporolactobacillus inulinus using sodium hydroxide as a neutralizing agent. Appl Microbiol Biotechnol. 2017. https://doi.org/10.1007/s00253-017-8120-0.

9. Silvia K, Norman K, Anja K, Ulf P. Biotechnological production of enantiomerically pure D-lactic acid. Appl Microbiol Biotechnol. 2016:100:9423-37.

10. Wang L, Zhao B, Liu B, Yu B, Ma C, Yang C, Su F, Hua D, Li Q, Ma Y, Xu P. Efficient production of L-lactic acid from corncob molasses, a waste byproduct in xylitol production, by a newly isolated xylose utilizing Bacillus sp. strain. Bioresour Technol. 2010;101:7908-15.

11. Peng L, Wang L, Che C, Yang G, Yu B, Ma Y. Bacillus sp. strain P38: an efficient producer of $\mathrm{L}$-lactate from cellulosic hydrolysate, with high tolerance for 2-furfural. Bioresour Technol. 2013;149:169-76.

12. Wang $Q$, Ingram LO, Shanmugam KT. Evolution of D-lactate dehydrogenase activity from glycerol dehydrogenase and its utility for D-lactate production from lignocellulose. PNAS. 2011;108:18920-5.

13. Sun $L$, Zhang $C$, Lyu $P$, Wang $Y$, Wang $L$, Yu B. Contributory roles of two L-lactate dehydrogenases for L-lactic acid production in thermotolerant Bacillus coagulans. Sci Rep. 2016;6:37916. https://doi.org/10.1038/ srep37916.

14. Kovács T, van Hartskamp M, Kuipers O, van Kranenburg R. Genetic tool development for a new host for biotechnology, the thermotolerant bacterium Bacillus coagulans. Appl Environ Microbiol. 2010;76:4085-8.

15. Zhu L, Xu X, Wang L, Dong H, Yu B. The D-lactate dehydrogenase from Sporolactobacillus inulinus also possessing reversible deamination activity. PLOS ONE. 2015:10:e0139066.

16. Nishihara K, Kanemori M, Kitagawa M, Yanagi H, Yura T. Chaperone coexpression plasmids: differential and synergistic roles of DnaK-DnaJ-GroE 
and GroEL-GroES in assisting folding of an allergen of Japanese cedar pollen, Cryj2, in Escherichia coli. Appl Environ Microbiol. 1998;64:1694-9.

17. Ishida N, Suzuki T, Tokuhiro K, Nagamori E, Onishi T, Saitoh S, Kitamoto K, Takahashi H. D-lactic acid production by metabolically engineered Saccharomyces cerevisiae. J Biosci Bieng. 2006;101:172-7.

18. Yamada R, Wakita K, Mitsui R, Ogino H. Enhanced D-lactic acid production by recombinant Saccharomyces cerevisiae following optimization of the global metabolic pathway. Biotechnol Bioeng. 2017. https://doi. org/10.1002/bit.26330.

19. Akita H, Nakashima N, Hoshino T. Production of D-lactate using a pyruvate-producing Escherichia coli strain. Biosci Biotechnol Biochem. 2017:81:1452-5

20. Ferain T, Hobbs JN, Richardson J, Bernard N, Garmyn D, Hols P, Allen $\mathrm{NE}$, Delcour J. Knockout of the two Idh genes has a major impact on peptidoglycan precursor synthesis in Lactobacillus plantarum. J Bacteriol. 1996;178:5431-7.

21. Rico J, Yebra MJ, Pérez-Martínez G, Deutscher J, Monedero V. Analysis of Idh genes in Lactobacillus casei BL23: role on lactic acid production. J Ind Microbiol Biotechnol. 2008;35:579-86.
22. Liu Y, Gao W, Zhao X, Wang JH, Garza E, Manow R, Zhou SD. Pilot scale demonstration of D-lactic acid fermentation facilitated by $\mathrm{Ca}(\mathrm{OH})_{2}$ using a metabolically engineered Escherichia coli. Bioresour Technol. 2014;169:559-65.

23. Van Kranenburg R, Van Hartskamp M, Heintz E, Anthonius J, Van Mullekom E, Snelders J. Genetic modification of homolactic thermophilic Bacilli. WO/2007/085443, 2007.

24. Qiu Z, Gao Q, Bao J. Constructing xylose-assimilating pathways in Pediococcus acidilactici for high titer D-lactic acid fermentation from corn stover feedstock. Bioresour Technol. 2017;245:1369-76.

25. Baek SH, Kwon EY, Kim YH, Hahn JS. Metabolic engineering and adaptive evolution for efficient production of D-lactic acid in Saccharomyces cerevisiae. Appl Microbiol Biotechnol. 2016;100:2737-48.

26. Zhou S, Yomano LP, Shanmugam KT, Ingram LO. Fermentation of $10 \%$ $(\mathrm{w} / \mathrm{v})$ sugar to $\mathrm{D}(-)$-lactate by engineered Escherichia coli B. Biotechnol Lett. 2005;27:1891-6.

27. Zheng H, Gong J, Chen T, Chen X, Zhao X. Strain improvement of Sporolactobacillus inulinus ATCC 15538 for acid tolerance and production of D-lactic acid by genome shuffling. Appl Microbiol Biotechnol. 2010;85:1541-9.

\section{Submit your next manuscript to BioMed Central and we will help you at every step:}

- We accept pre-submission inquiries

- Our selector tool helps you to find the most relevant journal

- We provide round the clock customer support

- Convenient online submission

- Thorough peer review

- Inclusion in PubMed and all major indexing services

- Maximum visibility for your research

Submit your manuscript at www.biomedcentral.com/submit 